\title{
Hypophosphatemia: an evidence-based approach to its clinical consequences and management
}

\author{
Jamshid Amanzadeh* and Robert F Reilly, Jr
}

\section{SUMMARY}

Optimal cellular function is dependent on maintenance of a normal serum phosphorus concentration. Serum phosphorus concentration is affected by several determinants, the most important of which is regulation of phosphorus reabsorption by the kidney. The majority of this reabsorption $(80 \%)$ occurs in the proximal tubule and is mediated by an isoform of the sodium-phosphate cotransporter (NaPi-II). Parathyroid hormone, via a variety of intracellular signaling cascades leading to NaPi-IIa internalization and downregulation, is the main regulator of renal phosphate reabsorption. Shift of phosphorus from extracellular to intracellular compartments, decreased gastrointestinal absorption, and increased urinary losses, are the primary mechanisms of hypophosphatemia, which affects approximately $2 \%$ of hospitalized patients. Hypophosphatemia has been implicated as a cause of rhabdomyolysis, respiratory failure, hemolysis and left ventricular dysfunction. With the exception of ventilated patients, there is little evidence that moderate hypophosphatemia has significant clinical consequences in humans, and aggressive intravenous phosphate replacement is unnecessary. By contrast, patients with severe hypophosphatemia should be treated. Intravenous repletion may be considered, especially for patients who have clinical sequelae of hypophosphatemia.

KEYWORDS hemolysis, hypophosphatemia, phosphorus, refeeding, rhabdomyolysis

\section{REVIEW CRITERIA}

We searched a variety of medical literature sources including PubMed, nephrology journals and textbooks, for information on phosphorus homeostasis, clinical consequences of hypophosphatemia, and side effects of parenteral phosphate administration.

\section{EBM}

J Amanzadeh is Staff Physician in the Section of Nephrology at Veterans Affairs North Texas Health Care System, and Assistant Professor in the Department of Medicine, The University of Texas Southwestern Medical Center at Dallas, Dallas, TX, USA. RF Reilly is Chief of the Section of Nephrology, Veterans Affairs North Texas Health Care System, and Fredric L Coe Professor of Nephrolithiasis Research in Mineral Metabolism, Department of Medicine, The University of Texas Southwestern Medical Center at Dallas, Dallas, TX, USA.

\section{Correspondence}

*Department of Medicine, The University of Texas Southwestern Medical Center, 5323 Harry Hines Blvd, Dallas, TX 75390, USA

jamshid.amanzadeh@utsouthwestern.edu

\section{Received 2 September 2005 Accepted 4 January 2006}

www.nature.com/clinicalpractice

doi:10.1038/ncpneph0124

\section{INTRODUCTION}

In recent years, numerous studies have evaluated the role of hyperphosphatemia in chronic kidney disease and dialysis patients. Less effort has gone into assessing the clinical significance of hypophosphatemia and scrutinizing its management. Identification of sodium-phosphate cotransporters and regulators of their expression and activity has shed light on the mechanisms of hypophosphatemia in diseases such as hyperparathyroidism, X-linked hypophosphatemia (XLH), autosomal dominant hypophosphatemic rickets and tumor-associated osteomalacia. Hypophosphatemia had previously been linked to rhabdomyolysis, hemolysis, and respiratory and cardiac failure. In spite of the prevalence of hypophosphatemia, these clinical consequences are not commonly encountered.

Severe hypophosphatemia might affect as few as $0.43 \%$ of hospitalized patients. Certain populations are likely to include a greater proportion of hypophosphatemic patients-for example, alcoholics $(0.9 \%)$, septic patients $(2.4 \%)$, malnourished patients (10.4\%), and patients with diabetic ketoacidosis $(14.6 \%)$. In a retrospective study, severe hypophosphatemia was associated with a fourfold increase in mortality. ${ }^{1}$ Evidence for excess morbidity associated with moderate hypophosphatemia is much less definitive. This review critically evaluates the clinical consequences of moderate $(1.0-2.5 \mathrm{mg} / \mathrm{dl}$ $[0.32-0.80 \mathrm{mmol} / \mathrm{l}])$ and severe $(<1.0 \mathrm{mg} / \mathrm{dl}$ $[<0.32 \mathrm{mmol} / \mathrm{l}])$ hypophosphatemia, as well as safety issues regarding rapid correction of a low serum phosphorus concentration.

\section{PHOSPHATE HOMEOSTASIS}

Phosphorus is an essential element. Phosphoruscontaining compounds have important roles in cell structure (cell membrane and nucleic acids), cellular metabolism (generation of ATP), regulation of subcellular processes (phosphorylation of key enzymes), and maintenance of acid-base homeostasis (urinary buffering). In the average adult, total body phosphorus content is $700 \mathrm{~g}$, 
of which $85 \%$ is in bone and teeth, $14 \%$ in soft tissues, and only 1\% in extracellular fluid. On average, approximately $800-1,400 \mathrm{mg}$ of phosphorus is ingested daily. Normal serum phosphorus concentration is $2.5-4.5 \mathrm{mg} / \mathrm{dl}$ $(0.80-1.45 \mathrm{mmol} / \mathrm{l}){ }^{2}$

The serum assay measures inorganic orthophosphates, of which $10 \%$ are bound to protein, $5 \%$ are complexed with calcium and magnesium, and $85 \%$ are $\mathrm{H}_{2} \mathrm{PO}_{4}{ }^{-}$and $\mathrm{HPO}_{4}{ }^{2-}$. In theory, there are potentially four species of free orthophosphate that can be measured $\left(\mathrm{H}_{3} \mathrm{PO}_{4}\right.$, $\mathrm{H}_{2} \mathrm{PO}_{4}{ }^{-}, \mathrm{HPO}_{4}{ }^{2-}$ and $\left.\mathrm{PO}_{4}{ }^{3-}\right)$, but at physiologic $\mathrm{pH}, \mathrm{H}_{3} \mathrm{PO}_{4}$ and $\mathrm{PO}_{4}{ }^{3-}$ concentrations are negligible. When dietary phosphorus intake is normal, the serum phosphorus concentration exhibits a circadian rhythm, rapidly decreasing in the early morning, reaching a nadir of $3.3 \pm 0.3 \mathrm{mg} / \mathrm{dl}(1.1 \pm 0.1 \mathrm{mmol} / 1)$ at $11: 00 \mathrm{~h}$, increasing to a plateau at $16: 00 \mathrm{~h}$, and peaking at $4.6 \pm 0.2 \mathrm{mg} / \mathrm{dl}(1.5 \pm 0.1 \mathrm{mmol} / \mathrm{l})$ between $1: 00 \mathrm{~h}$ and 3:00 h. ${ }^{3}$ In plasma, phosphorus circulates in monovalent $\left(\mathrm{H}_{2} \mathrm{PO}_{4}{ }^{-}\right)$and divalent $\left(\mathrm{HPO}_{4}{ }^{2-}\right)$ forms. At systemic $\mathrm{pH}$, the divalent form predominates. In urine, phosphate is an effective buffer, a function of its relatively high tubular concentration and PKa of 6.8, which is close to the $\mathrm{pH}$ of urine under normal conditions.

Maintaining normal phosphorus concentrations is essential for optimal cellular function. The kidney and (to a lesser extent) the small intestine are the main organs that maintain phosphorus homeostasis. A large proportion of dietary phosphate is absorbed from the gastrointestinal tract and excreted in urine. In proximal tubule cells and enterocytes, type II sodium-phosphate cotransporters (NaPi-II) are expressed in the apical membrane; their activity rate limits transepithelial phosphate transport. NaPi-II expression in both cell types is controlled by hormones and metabolic factors in response to homeostatic needs. ${ }^{4}$

Intestinal phosphorus absorption occurs through both cellular and paracellular pathways. Transepithelial phosphate transport across intact intestinal epithelium is driven by an active sodium-dependent process. Compartmental analysis indicates that phosphate entering the cell across the brush border is transported through the cell and sequestered from the intracellular phosphorus pool. The form of phosphorus absorbed is not known, but both luminal $\mathrm{pH}$ and ionic strength determine the species available for absorption. ${ }^{5}$ A low phosphorus diet and
$1,25(\mathrm{OH})_{2}$ vitamin $\mathrm{D}_{3}$ are the two most important positive regulators of the intestinal isoform (NaPi-IIb). A low phosphorus diet stimulates renal 1a-hydroxylase, which increases levels of $1,25(\mathrm{OH})_{2}$ vitamin $\mathrm{D}_{3}$. Recent studies of transgenic mice demonstrated that adaptation of NaPi-IIb to a low phosphorus diet occurs independently of vitamin D. ${ }^{6,7}$

Metabolic acidosis, estrogen and epidermal growth factor (EGF) enhance expression of NaPi-IIb. 8 A novel signaling pathway in regulation of intestinal phosphate transport involves serum and glucocorticoid-inducible kinase 1, and the ubiquitin ligase Nedd4-2. Ubiquitination of target proteins tags them for removal from the cell membrane and for degradation in proteasomes. Serum and glucocorticoid-inducible kinase 1 stimulates phosphate transport, at least in part, by phosphorylating Nedd4-2, thereby inhibiting binding of this ubiquitin ligase to NaPi-IIb. ${ }^{10}$ $\mathrm{NaPi}-\mathrm{IIb}$ is not ubiquitinated and its expression in the membrane is increased.

In the kidney, phosphorus homeostasis is regulated primarily via control of phosphorus reabsorption across the proximal tubule apical membrane. When levels of dietary phosphorus are normal and parathyroid function is intact, about $80 \%$ of filtered phosphate is reabsorbed. ${ }^{5}$ Low dietary $\mathrm{P}_{\mathrm{i}}$ intake leads to near complete reabsorption of filtered $\mathrm{P}_{\mathrm{i}}$, whereas high dietary $\mathrm{P}_{\mathrm{i}}$ intake results in decreased proximal tubule $\mathrm{P}_{\mathrm{i}}$ reabsorption. ${ }^{11}$ Three sodium-phosphorus cotransporters are expressed in proximal tubule cells. NaPi-I and NaPi-II are located in the apical membrane, whereas NaPi-III is thought to be expressed in the basolateral membrane, where it functions as a 'housekeeping' cotransporter.

There are three isoforms of NaPi-II: a, b and c. NaPi-IIa and NaPi-IIb are electrogenic. $\mathrm{NaPi}$-IIa and NaPi-IIc are expressed exclusively in the brush-border membrane of proximal tubule cells, whereas NaPi-IIb is responsible for intestinal absorption of phosphate. About 70\% of proximal tubule phosphate reabsorption is mediated by NaPi-IIa. Parathyroid hormone (PTH) is the primary regulator of phosphate reabsorption in kidney.

Hormonal (PTH and atrial natriuretic peptide) and nonhormonal (nitric oxide) factors activate intracellular signaling cascades leading to internalization of NaPi-IIa. Internalization occurs via CLATHRIN-coated structures, early endosomes and, subsequently, lysosomal degradation of

\section{GLOSSARY}

PKa

The negative logarithm of the dissociation constant, which represents the tendency of a substance to reversibly separate into smaller constituents

PROTEASOMES

The protease part of the ubiquitin system, which is the proteolytic system in eukaryotic cells that degrades polyubiquitylated proteins

\section{CLATHRIN}

A primary protein constituent of the 'coats' of endocytic vesicles that can bind specific membrane receptors 


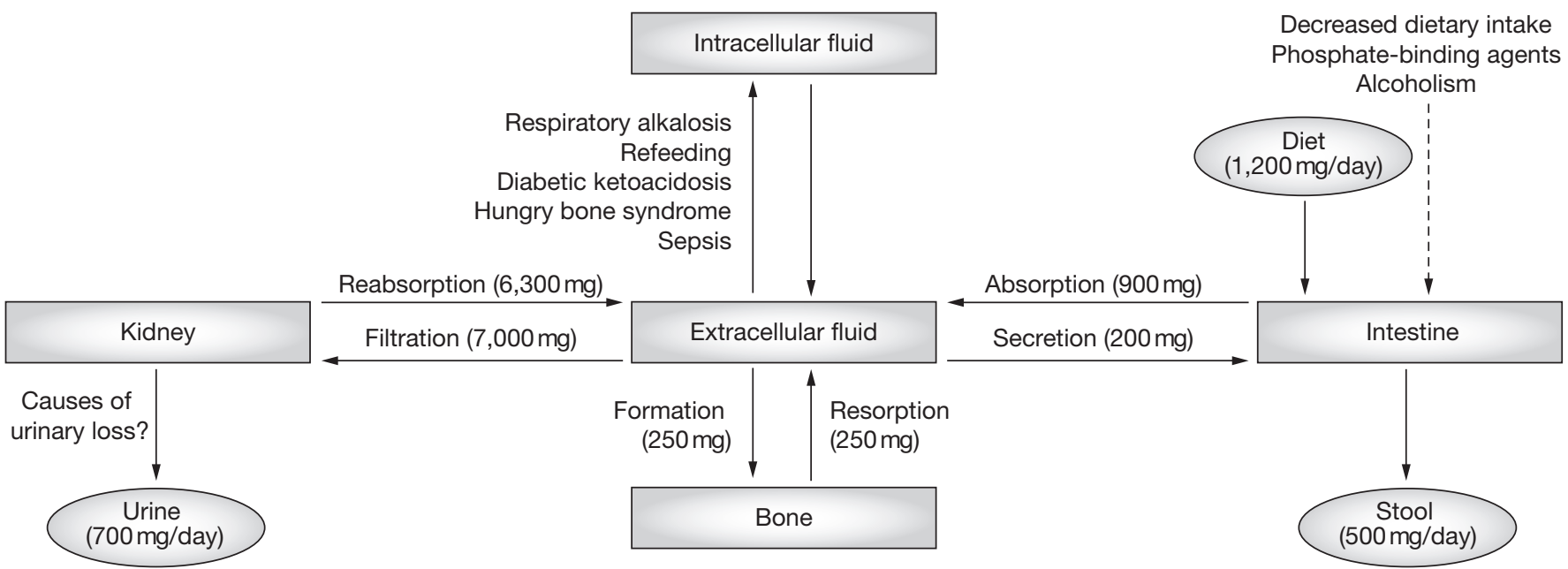

Figure 1 Phosphate fluxes and causes of hypophosphatemia. Decreased intake (e.g. as an effect of phosphate-binding agents), redistribution (e.g. into the intracellular compartment in response to respiratory alkalosis) and increased excretion (e.g. in the urine) of phosphorus are the mechanisms underlying hypophosphatemia.

\section{GLOSSARY} PHOSPHATONINS

Hormones that regulate phosphate metabolism (e.g. fibroblast growth factor 23 and frizzled-related protein 4)
$\mathrm{NaPi}$-IIa. In renal proximal tubule cells, PTH binding to apical receptors activates protein kinase $\mathrm{C}$ (PKC), and binding to basolateral PTH receptors activates both $\mathrm{PKC}$ and cyclic $\mathrm{AMP} /$ protein kinase A (PKA) pathways. The exact steps involved in internalization of NaPi-IIa after PKA and PKC activation are not clear; however, mitogen-activated protein (MAP) kinase (extracellular receptor kinase ERK1/2) might be involved. ERK1/2 inhibition prevents PTHinduced internalization of NaPi-IIa, and also completely or partially prevents NaPi-IIa downregulation upon pharmacologic activation of PKA and PKC, respectively. This mechanism indicates that the PKA and PKC pathways converge, at least partially, at the level of ERK1/2. ${ }^{12}$

Insulin enhances proximal tubule $\mathrm{P}_{\mathrm{i}}$ reabsorption by stimulating brush-border membrane $\mathrm{Na}-\mathrm{P}_{\mathrm{i}}$ cotransport, and prevents the phosphaturic action of PTH. Growth hormone stimulates proximal tubule $\mathrm{Na}-\mathrm{P}_{\mathrm{i}}$ cotransport, an effect that is partially mediated by insulinlike growth factor 1 (IGF1). EGF stimulates $P_{i}$ reabsorption in perfused proximal tubules, but inhibits $\mathrm{P}_{\mathrm{i}}$ transport in opossum kidney cells. Thyroid hormone increases proximal tubule $\mathrm{P}_{\mathrm{i}}$ reabsorption by specifically enhancing brush-border membrane $\mathrm{Na}-\mathrm{P}_{\mathrm{i}}$ cotransport. Calcitonin and glucocorticoids inhibit proximal tubule brush-border reabsorption. ${ }^{11}$

Several pHosphatonins-including fibroblast growth factor 23 (FGF23), frizzled-related protein 4 (FRP4) and matrix extracellular phosphoglycoprotein (MEPE) — associated with different pathophysiological states of renal phosphate handling, also influence apical expression of NaPi-IIa. ${ }^{13}$ Reduced or increased phosphate intake results in increased or decreased expression of NaPi-IIa, respectively.

\section{MECHANISMS OF HYPOPHOSPHATEMIA}

Serum phosphorus concentration is determined by several factors (Figure 1). Dietary phosphorus intake, stage of growth and time of day contribute to the variability of fasting serum phosphorus concentrations. Hypophosphatemia is observed in approximately $2 \%$ of hospitalized patients, ${ }^{14}$ and can be related to decreased intestinal absorption of phosphorus, redistribution of phosphorus from the extracellular to the intracellular compartment, increased loss of phosphorus through the kidneys, or any combination of these processes. ${ }^{2}$ The most common manifestation of hypophosphatemia in hospitalized patients is secondary to redistribution of phosphorus as a result of respiratory alkalosis.

\section{Decreased intake of phosphorus}

It is rare for decreased dietary intake alone to cause hypophosphatemia, probably because renal phosphate reabsorption is enhanced to compensate for decreased intake. On the other hand, malabsorption and phosphate binders can decrease intestinal phosphate absorption and result in hypophosphatemia. ${ }^{15,16}$ In a study of normal human volunteers it took 
approximately 3 months for the combination of a low phosphorus diet and antacids to reduce serum phosphorus concentration to $1.0 \mathrm{mg} / \mathrm{dl}$ $(0.3 \mathrm{mmol} / \mathrm{l}) .{ }^{17}$

\section{Redistribution of phosphorus}

Hypophosphatemia secondary to phosphorus redistribution is commonly caused by respiratory alkalosis and refeeding of malnourished patients. Acute respiratory alkalosis and metabolic alkalosis decrease serum phosphorus concentration. The reduction is much greater in respiratory alkalosis than in metabolic alkalosis of comparable severity. ${ }^{18,19}$ During respiratory alkalosis, intracellular $\mathrm{CO}_{2}$ decreases, causing intracellular $\mathrm{pH}$ to rise. This mechanism stimulates the glycolytic pathway, specifically phosphofructokinase, a key rate-limiting enzyme of glycolysis. Production of sugar phosphates is enhanced, which in turn induces intracellular phosphorus entry, thus decreasing serum phosphorus concentration. ${ }^{5}$

Respiratory alkalosis enhances phosphorus uptake by muscle. The kidney responds by increasing phosphate reabsorption, independent of serum phosphorus concentration and becomes refractory to the phosphaturic effect of PTH. This refractoriness is due to decreased $\mathrm{pCO}_{2}$ rather than to the concomitant extracellular alkalosis. ${ }^{19}$ Hypophosphatemia is also associated with other medical conditions of which hyperventilation is a feature, such as sepsis, heat stroke and hepatic coma. ${ }^{20-22}$

One of the earliest reports of refeeding syndrome was in starved Japanese prisoners of war. ${ }^{23}$ Patients with anorexia nervosa, and those subject to prolonged fasting or parenteral or enteral feeding after major surgery, are well recognized modern counterparts of the starved prisoners. The proposed mechanism of hypophosphatemia in these patients is increased insulin release that causes an intracellular shift in distribution of phosphorus. Enhanced synthesis of ATP, 2,3-diphosphoglycerate (DPG) and creatine phosphokinase (CPK) might contribute to the hypophosphatemia associated with refeeding syndrome. ${ }^{24}$ Early studies in dogs and humans showed that the serum phosphorus concentrations of normal dogs and men drop after ingestion or infusion of glucose. Fiske was the first to call attention to this relationship between carbohydrates and serum phosphorus concentration. ${ }^{25}$ Sokhey found that the decrease in urinary phosphate excretion after infusion of glucose was almost as great as that induced by insulin. ${ }^{26}$ Glucose injections in dogs made diabetic by pancreatectomy did not cause serum phosphorus concentration to change unless insulin was coinjected. ${ }^{27}$ In the same study of a series of hepatectomized animals, hypophosphatemia after glucose infusion was observed, but not in animals from which all striated muscle had been removed. The investigators concluded that the site of phosphorus sequestration is muscle.

Cellular sequestration of phosphorus and hypophosphatemia are also observed in leukemia patients with rapidly replicating tumor cells, following hematopoietic reconstitution after allogeneic peripheral blood stem cell transplantation, and after parathyroidectomy (the so-called 'hungry bone syndrome'). ${ }^{28-30}$ Intracellular shifts of phosphorus secondary to correction of respiratory acidosis can result in hypophosphatemia after institution of mechanical ventilation in chronic obstructive pulmonary disease (COPD) patients. ${ }^{31}$ This hypophosphatemia occurs upon correction to normal $\mathrm{pH}$.

\section{Increased urinary excretion of phosphorus}

Enhanced urinary excretion of phosphate occurs in patients with primary hyperparathyroidism, as well as in those with secondary hyperparathyroidism associated with hypocalcemia and intact renal function. PTH signal transduction via cAMP-dependent and cAMP-independent pathways promotes internalization of $\mathrm{NaPi}$-IIa cotransporters from the cell membrane and their subsequent degradation. This process decreases Na-Pi cotransport activity. ${ }^{32}$ The amino-terminal region of PTH-related protein has significant homology with that of PTH. As such, both substances have a similar effect on excretion of urinary phosphorus and nephrogenous cAMP in vivo, and on sodium-dependent phosphate transport in brush-border membrane vesicles in vitro. ${ }^{33}$

Hypophosphatemia associated with primary hyperparathyroidism is usually of moderate severity; increased urinary phosphate excretion is balanced by mobilization of phosphate from bone and enhanced intestinal absorption. Serum phosphorus concentrations are seldom less than $2.0 \mathrm{mg} / \mathrm{dl}(0.6 \mathrm{mmol} / 1)$ unless patients' phosphorus intake is low or they simultaneously ingest phosphate-binding antacids. ${ }^{34}$

Impaired reabsorption of phosphate by proximal tubules and subsequent hypophosphatemia can
GLOSSARY $\mathrm{pCO}_{2}$ Partial pressure of carbon dioxide 
be part of the Fanconi syndrome. In addition to traditional, well known causes of this syndrome (inheritance, heavy metals, monoclonal gammopathy and metabolic disorders), new causative culprits are emerging, including antiretroviral medications (e.g. tenofovir, cidofovir, adefovir dipivoxil) and aristocholic acid (found in Chinese herbal medicines). ${ }^{35,36}$ Post-transplant hypophosphatemia is also associated with increased renal excretion of phosphate. A non-PTH circulating serum factor (possibly FGF23) that increases fractional excretion of phosphate in the initial stages after successful kidney transplantation might be responsible. ${ }^{37}$ Steroid therapy in the early post-transplant period and persistent hyperparathyroidism are other potential causes of post-transplant hypophosphatemia. ${ }^{38}$

Four other conditions must be considered in the differential diagnosis of renal phosphate wasting: XLH, autosomal-dominant hypophosphatemic rickets, tumor-associated osteomalacia and fibrous dysplasia. The primary defects in XLH and autosomal-dominant hypophosphatemic rickets are inactivating mutations of a zinc metalloendopeptidase (PHEX) and activating mutations of FGF23, respectively. Tumor-induced (oncogenic) osteomalacia is a rare clinicopathologic entity in which the clinical signs and symptoms of osteomalacia and the specific laboratory abnormalities of hypophosphatemia, phosphaturia and low serum levels of $1,25(\mathrm{OH})_{2}$ vitamin $\mathrm{D}_{3}$, are associated with a neoplasm. ${ }^{39}$ Several proteins expressed in tumors (MEPE, FGF23, and FRP4) have emerged as potential mediators of the bone-renal pathophysiology in oncogenic osteomalacia. ${ }^{40}$ Fibrous dysplasia patients sometimes suffer from concomitant hypophosphatemic rickets/osteomalacia, resulting from phosphate wasting. FGF23 originating from dysplasic tissue might cause hypophosphatemia in these patients. ${ }^{41}$

\section{CLINICAL CONSEQUENCES OF HYPOPHOSPHATEMIA Rhabdomyolysis}

The effect of chronic hypophosphatemia on muscle function and composition in dogs fed a low phosphorus diet for 4 weeks has been examined. Average resting transmembrane electrical potential difference fell, and muscle $\mathrm{Na}^{+}, \mathrm{Cl}^{-}$and water content rose. After 4 weeks of phosphorus repletion, all of these variables returned toward control values. The authors concluded that moderate phosphorus depletion can induce reversible changes in the composition of skeletal muscle and transmembrane potential in the dog. ${ }^{42}$ In hypophosphatemic dogs a subclinical myopathy might set the stage for rhabdomyolysis if acute, severe hypophosphatemia is superimposed. ${ }^{43}$ In another study of phosphate-depleted rats, mitochondrial respiration and oxidative phosphorylation in skeletal muscle were impaired without change to adenine nucleotide levels. ${ }^{44}$

Most human cases of hypophosphatemiaassociated rhabdomyolysis have been associated with alcoholism. ${ }^{45-49}$ A combination of pathophysiological mechanisms - inappropriate phosphaturia, enhanced cellular uptake of phosphorus, increased gastrointestinal phosphate $\operatorname{loss}^{50}$ contribute to hypophosphatemia in alcoholic patients. In hospitalized sufferers these factors can be compounded by alcohol withdrawal or alcoholic ketoacidosis. Hyperventilation with resultant respiratory alkalosis and infusion of dextrose-containing fluid exacerbates hypophosphatemia by stimulating movement of phosphorus into cells. Hypophosphatemia can accentuate the direct effect of alcohol on striated muscle and worsen alcoholic myopathy. ${ }^{5,51}$ In two studies, however, no relationship was found between hypophosphatemia and serum CPK or myoglobin levels. 52,53

There are reports of a link between rhabdomyolysis and hypophosphatemia in cases of anorexia nervosa, theophylline toxicity, acute barium poisoning and toluene sniffing. ${ }^{54-56}$ In the largest series, $36 \%$ of 129 patients admitted to hospital with hypophosphatemia were diagnosed with rhabdomyolysis. Hypophosphatemic rhabdomyolysis was defined as an increase in the concentration of CPK to more than 1.5 times the upper limit of normal with no other cause that subsequently normalized. Mean serum phosphorus concentration was $1.6 \mathrm{mg} / \mathrm{dl}$ ( $0.5 \mathrm{mmol} / \mathrm{l})$ and mean CPK concentration was $872 \pm 110 \mathrm{U} / \mathrm{l}$. Rhabdomyolysis was diagnosed on the basis of routine laboratory testing; no patient had signs or symptoms. Elevated serum concentrations of sodium, chloride, glucose, blood urea nitrogen and uric acid were associated with the occurrence of rhabdomyolysis in the hypophosphatemic state. ${ }^{48}$

Another musculoskeletal condition associated with hypophosphatemia is hypophosphatemic osteomalacia. Patients with this condition generally have proximal muscle weakness, high levels of alkaline phosphatase, normal levels of CPK, low or normal serum calcium concentrations, 
and low serum phosphorus concentrations. Osteomalacic muscle weakness is not myopathic; rather, it is due to nonspecific atrophy probably caused by disuse and malnutrition, especially in states of nutritional deficiency. ${ }^{57}$ The small number of case reports and coexistent metabolic abnormalities that have been implicated as etiologies of rhabdomyolysis make it difficult to establish a strong cause-and-effect relationship between hypophosphatemia and rhabdomyolysis in any individual patient. Most case report patients have had moderate hypophosphatemia. It seems likely that moderate and severe hypophosphatemia are frequently associated with mild subclinical rhabdomyolysis that infrequently results in clinical sequelae.

\section{Hemolysis}

Hypophosphatemia can alter red cell glycolytic intermediates and oxygen transport. These alterations include markedly reducing levels of erythrocyte ATP and 2,3-DPG, which enhances the affinity of oxygen for hemoglobin (reflected as a drop in p50). The fall in ATP decreases red cell hexokinase activity and increases phosphofructokinase activity. As a result, erythrocyte concentrations of glucose-6-phosphate and fructose-6-phosphate are reduced, and more triose phosphates accumulate. ${ }^{58,59}$ ATP is required for maintenance of erythrocyte biconcavity and viability in the circulation. ${ }^{60,61}$ ATP depletion has been associated with decreased cell membrane deformability and life span, ${ }^{62}$ but there have been few human case reports of hypophosphatemia associated with hemolytic anemia (phosphorus concentration $\leq 1.7 \mathrm{mg} / \mathrm{dl}[0.54 \mathrm{mmol} / \mathrm{l}]) .{ }^{63-66} \mathrm{In}$ these few cases, serum phosphorus concentration was either rapidly falling (refeeding) or severely depressed $(\leq 0.2 \mathrm{mg} / \mathrm{dl}[0.06 \mathrm{mmol} / \mathrm{l}])$.

\section{Leukocyte dysfunction}

Hypophosphatemia can also reduce the ATP content of leukocytes and ameliorate neutrophil phagocytosis, intracellular killing, consumption of oxygen and generation of superoxide during phagocytosis. ${ }^{67,68}$ The high rate of sepsis during hyperalimentation might result, in part, from acquired dysfunctions in leukocyte chemotaxis and phagocytosis, secondary to hypophosphatemia. That these in vitro studies are relevant to hyperalimentation-associated hypophosphatemia has been indicated by observation of a 44-year-old woman. In this patient with assumed occult malignancy, development of hypophosphatemia (serum phosphorus concentration of $2.0 \mathrm{mg} / \mathrm{dl}$ [0.6 mmol/l]) 2 days after hyperalimentation was accompanied by pneumonia and empyema. Leukocyte studies revealed diminished ATP levels (to roughly half normal) and impaired chemotaxis. Incubation with phosphate and adenosine reversed these changes. After termination of hyperalimentation and phosphate supplements, serum phosphorus concentration, leukocyte ATP and leukocyte chemotaxis rapidly returned to normal and pneumonia and empyema were resolved. ${ }^{67}$

In another study, the relationship between serum phosphorus concentration and intracellular concentrations of inorganic phosphorus and ATP in red blood cells, leukocytes and platelets of patients with hypophosphatemia secondary to vitamin-D-resistant rickets was studied. Six patients with low serum phosphorus concentrations ( $<3.1 \mathrm{mg} / \mathrm{dl}[1 \mathrm{mmol} / \mathrm{l}])$ were included. Intracellular ATP levels were maintained within normal range, even though plasma and intracellular phosphorus concentrations were low. ${ }^{69}$ So, although there is good evidence from animal models that hypophosphatemia impairs leukocyte function, there is no compelling data in animals or humans that this impairment is associated with an increased risk of infection.

\section{Respiratory failure}

Hypophosphatemia might cause respiratory failure. In one study, maximal inspiratory and expiratory pressures of hospitalized patients with serum phosphate concentrations less than $2.5 \mathrm{mg} / \mathrm{dl}(0.8 \mathrm{mmol} / \mathrm{l})$ were measured at the bedside. These measurements were repeated daily during phosphate repletion until serum phosphorus concentration reached the normal range. In most hypophosphatemic patients-but no normophosphatemic patients-respiratory muscle weakness (defined as low maximal inspiratory pressure or low maximal expiratory pressure) was detected. Respiratory muscle strength improved after phosphate repletion. The mean serum phosphorus concentration of these 23 patients was $1.9 \pm 0.4 \mathrm{mg} / \mathrm{dl}(0.61 \pm 0.13 \mathrm{mmol} / \mathrm{l})$. Twelve patients had a serum phosphorus concentration of up to $2.0 \mathrm{mg} / \mathrm{dl}(0.64 \mathrm{mmol} / \mathrm{l})$ and four had a serum phosphorus concentration between 1.0 and $1.5 \mathrm{mg} / \mathrm{dl}(0.3-0.5 \mathrm{mmol} / \mathrm{l})$. There was a correlation between the decrease in maximal inspiratory pressures and the severity of hypophosphatemia (Figure 2). ${ }^{70}$

\section{GLOSSARY} p50

The partial pressure of oxygen at which hemoglobin is $50 \%$ saturated with oxygen 
www.nature.com/clinicalpractice/neph

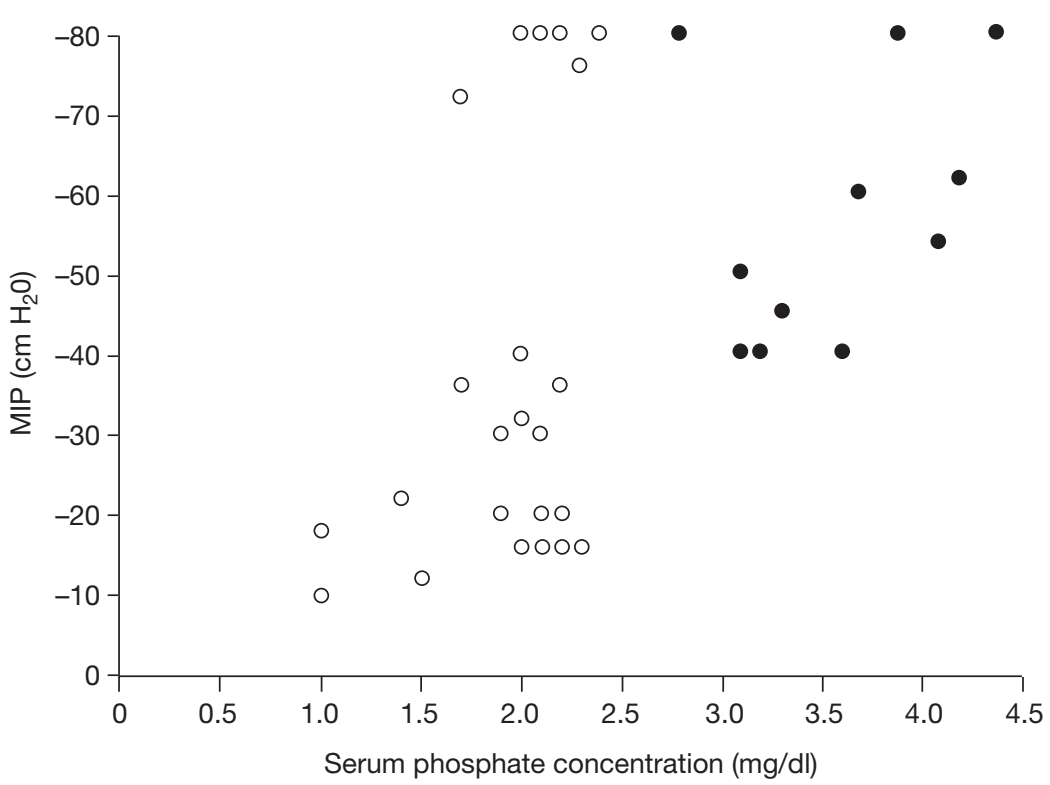

Figure 2 Correlation between the decrease in maximal inspiratory pressures and the severity of hypophosphatemia. Maximal inspiratory pressures at study entry are shown, plotted as a function of initial serum phosphate concentrations for hypophosphatemic patients (open symbols) and normophosphatemic control patients (filled symbols); $r=0.50, P<0.02$. Reproduced with permission from reference 70 () (1988) Excerpta Medica, Inc. MIP, maximal inspiratory pressure.

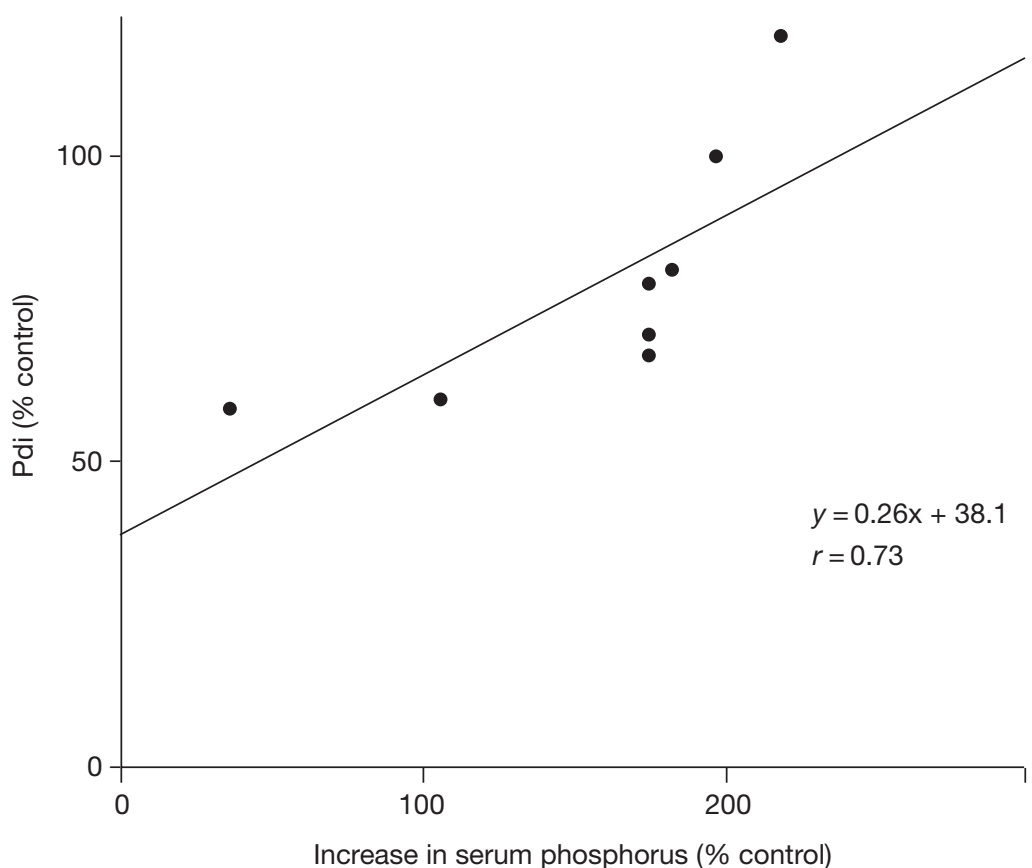

Figure 3 Hypophosphatemia impairs the contractile properties of the diaphragm during acute respiratory failure. Individual increases in transdiaphragmatic pressure are generated during phrenic stimulation after correction of hypophosphatemia, as a function of the concomitant increase in serum phosphorus concentration. The solid line represents the computed regression for the experimental data. The coefficient of correlation $(r=0.73)$ was significant $(P<0.0005)$. Reproduced with permission from reference 71 (C) (1985) Massachusetts Medical Society. Pdi, increases in transdiaphragmatic pressure.
Hypophosphatemia also impairs the contractile properties of the diaphragm during acute respiratory failure. ${ }^{71}$ In a group of eight patients with moderate hypophosphatemia and respiratory failure or mechanical ventilation, diaphragmatic function was evaluated prior to and following infusion of phosphorus. Transdiaphragmatic pressure generated at functional residual capacity during bilateral supramaximal electrical stimulation of the phrenic nerves was measured. Transdiaphragmatic pressure increased in all eight patients and the increase correlated with the change in serum phosphorus concentration (Figure 3). ${ }^{71}$ In another study, hypophosphatemia $(\leq 2.5 \mathrm{mg} / \mathrm{dl}[0.8 \mathrm{mmol} / \mathrm{l}])$ was found in $34(21.5 \%)$ of 158 patients with respiratory illness; hypophosphatemia was not associated with the severity of the respiratory illness. Indices of renal phosphorus handling indicated inappropriately high rates of phosphate excretion given the degree of hypophosphatemia (low percentage tubular reabsorption of phosphorus, and low renal phosphate threshold/glomerular filtration rate values). The prevalence of hypophosphatemia was significantly greater among COPD patients taking one or more drugs that stimulate renal phosphate excretion (xanthine derivatives, corticosteroids, loop diuretics, $\beta 2$-adrenergic bronchodilators). Despite the phosphorus content of both peripheral and respiratory muscles of COPD patients being reduced in another series, in this study a relationship between muscle and serum phosphorus concentrations was demonstrable in the case of peripheral muscles only. ${ }^{72,73}$

Hypophosphatemia as a cause of respiratory failure and refractory weaning from the ventilator has been reported, albeit infrequently. Most patients have had severe hypophosphatemia $(\leq 1.0 \mathrm{mg} / \mathrm{dl}[0.3 \mathrm{mmol} / \mathrm{l}])$. Weaning from the ventilator was achieved following correction of hypophosphatemia. ${ }^{74-77}$ Diaphragmatic contractility can be improved by correcting severe and moderate hypophosphatemia. We recommend evaluating the serum phosphorus concentration carefully in intubated patients and correcting it to within the normal range if possible.

\section{Impaired myocardial performance}

Reversible depression of myocardial performance in dogs with moderate diet-induced phosphorus depletion (serum phosphorus concentration decreased from $5.1 \pm 0.1 \mathrm{mg} / \mathrm{dl}[1.63 \pm 0.03 \mathrm{mmol} / \mathrm{l}]$ 
on day 0 to $0.9 \pm 0.1 \mathrm{mg} / \mathrm{dl}[0.28 \pm 0.03 \mathrm{mmol} / 1]$ on day 35) has been demonstrated. ${ }^{78}$ Human studies of the effect of hypophosphatemia on myocardial function, however, show conflicting results. Cardiac output, as thermodilution and calculated stroke work, was measured in seven patients with severe hypophosphatemia before, during and after repletion with an intravenous potassium phosphate solution. Return of serum phosphorus concentration to normal improved myocardial stroke work independently of the Starling effect. ${ }^{79}$ In a later study, however, hypophosphatemia alone did not cause left ventricular dysfunction. ${ }^{80}$ One explanation for this discrepancy might be the different mean serum phosphorus concentrations of patients in the two studies $(0.97 \mathrm{mg} / \mathrm{dl}$ $[0.31 \mathrm{mmol} / \mathrm{l}]$ in the first and $1.88 \mathrm{mg} / \mathrm{dl}$ $[0.61 \mathrm{mmol} / \mathrm{l}]$ in the second). The validity of this explanation was confirmed by Davis et al., who showed that improvement in left ventricular performance after correction of hypophosphatemia occurred only in patients with severe hypophosphatemia $(0.90 \pm 0.15 \mathrm{mg} / \mathrm{dl}$ $[0.29 \pm 0.05 \mathrm{mmol} / \mathrm{l}])$ and not in those with moderate hypophosphatemia $(1.40 \pm 0.11 \mathrm{mg} / \mathrm{dl}$ $[0.45 \pm 0.03 \mathrm{mmol} / \mathrm{l}]) .{ }^{81}$

To determine whether chronic moderate hypophosphatemia causes myocardial dysfunction, 10 patients aged 5-18 years with X-linked hypophosphatemic rickets and a mean serum phosphorus concentration of $2.6 \pm 0.5 \mathrm{mg} / \mathrm{dl}$ $(0.83 \pm 0.16 \mathrm{mmol} / \mathrm{l})$ were examined. There was no evidence of left ventricular dysfunction (measured by echocardiography) in this human model of clinically significant long-standing hypophosphatemia. The lowest serum phosphorus concentration in this group of patients was $1.5 \mathrm{mg} / \mathrm{dl}(0.5 \mathrm{mmol} / \mathrm{l}){ }^{82} \mathrm{In}$ another study, low serum phosphorus concentration $(<2.6 \mathrm{mg} / \mathrm{dl}$ $[0.8 \mathrm{mmol} / \mathrm{l}])$ was a significant predictor of ventricular tachycardia in patients with a recent myocardial infarction. ${ }^{83}$

Correction of severe hypophosphatemia increases myocardial contractility by approximately $20 \%$. The effect is variable between patients; some have minimal or no response, whereas large effects are observed in others. Moderate hypophosphatemia probably has very little effect on myocardial contractility.

\section{Diabetic ketoacidosis}

Hypophosphatemia is associated with impaired glucose metabolism in both hyperglycemic and euglycemic states. This effect is primarily a reflection of decreased tissue sensitivity to insulin. ${ }^{84}$ Serum phosphorus concentration can be normal or slightly elevated in patients with untreated diabetic ketoacidosis, despite the fact that renal phosphate excretion is increased. Seldin et al. assessed the metabolism of glucose and cellular balance of electrolytes in diabetic acidosis. Translocation of phosphorus from the intracellular to the extracellular fluid was most rapid during the early stages, falling during treatment of ketoacidosis with insulin and fluids. Initial phosphaturia also decreased after correction of ketoacidosis. ${ }^{85}$

In another study, ketoacidosis inhibited the glycolytic enzyme phosphofructokinase in erythrocytes. As a consequence, the concentrations of glycolytic intermediates proximal to this step were increased; levels of distal intermediates, including 2,3-biphosphoglycerate, were decreased. Although administration of insulin produced hypophosphatemia within $8-12 \mathrm{~h}$, which persisted for $24 \mathrm{~h}$ or more, in vitro studies showed that acidemia was primarily responsible for the inhibition of phosphofructokinase. ${ }^{86}$ Once again, while acute hemolytic anemia secondary to severe hypophosphatemia in diabetic ketoacidosis has been reported, ${ }^{87}$ this is not a common clinical finding.

\section{Perturbed central nervous system}

There are several case reports indicating an association between hypophosphatemia and neurological problems such as altered mental status and polyneuropathy including cranial nerves, seizure and central pontine myelinolysis. ${ }^{88-90}$ Muscular weakness, paresthesia, convulsions and coma were reported in three starved patients who developed hypophosphatemia (mean serum phosphorus concentration $\quad 0.3 \mathrm{mg} / \mathrm{dl} \quad[0.1 \mathrm{mmol} / \mathrm{l}]$ ) during parenteral hyperalimentation. ${ }^{91}$ In most cases of neurological deficit associated with hypophosphatemia, serum phosphorus concentrations were below $1.0 \mathrm{mg} / \mathrm{dl}(0.3 \mathrm{mmol} / \mathrm{l})$. A few cases of proximal muscle weakness have been associated with serum phosphorus concentrations of $2.2-3.2 \mathrm{mg} / \mathrm{dl}(0.7-1.0 \mathrm{mmol} / \mathrm{l}) .^{92}$

\section{MANAGEMENT OF HYPOPHOSPHATEMIA}

One must keep in mind that serum phosphorus concentration might not be a reliable indicator of total body phosphorus, because most phosphorus is stored intracellularly. ${ }^{2}$ The first 


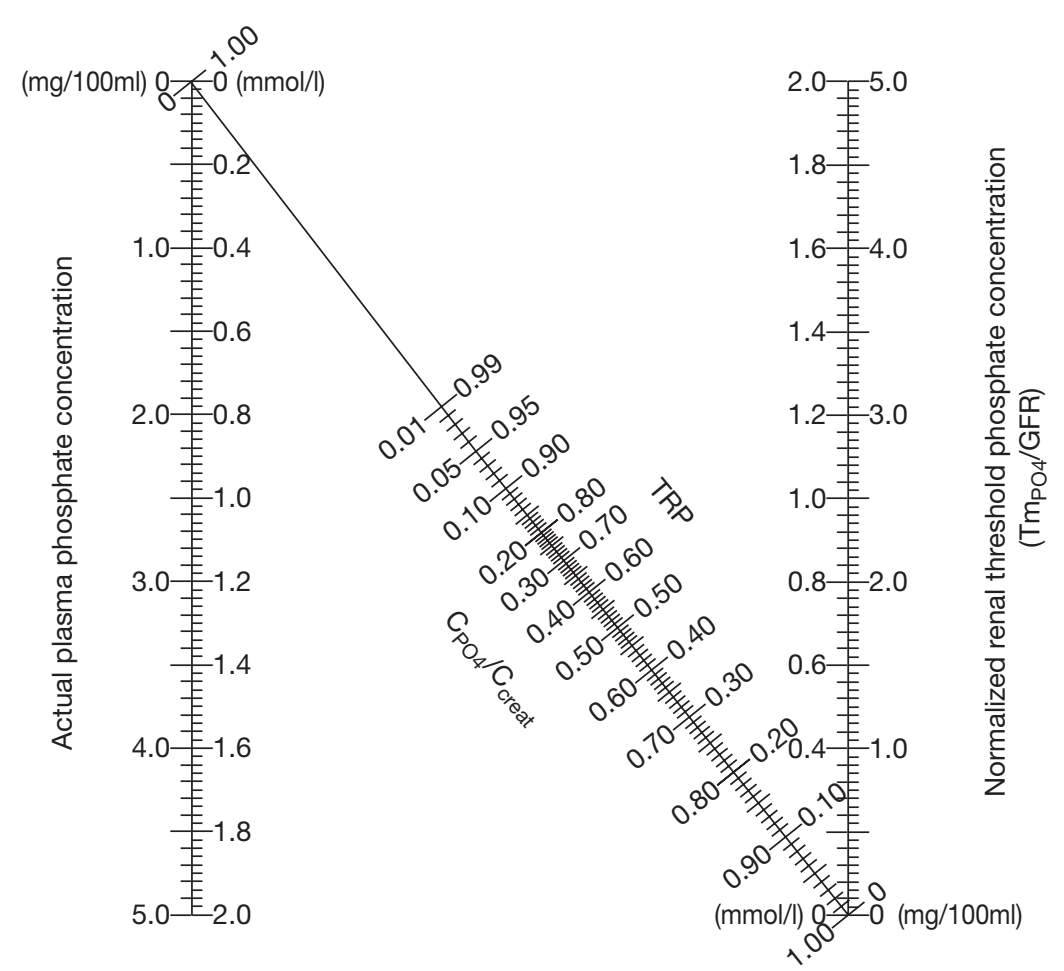

Figure 4 Nomogram for derivation of normalized renal threshold phosphate concentration. Reproduced with permission from reference 94 (C) (1975) Elsevier. $\mathrm{C}_{\mathrm{PO} 4}$, phosphate clearance; $\mathrm{C}_{\text {creat }}$, creatinine clearance; GFR, glomerular filtration rate; $\mathrm{Tm}_{\mathrm{PO} 4}$, renal phosphate threshold; TRP, fractional tubular reabsorption of phosphate. of phosphate such as phosphate clearance $\left(\mathrm{C}_{\mathrm{PO} 4}\right)$, phosphate : creatinine clearance ratio $\left(\mathrm{C}_{\mathrm{PO}}: \mathrm{C}_{\text {creat }}\right)$ and fractional tubular reabsorption of phosphate, fail to discriminate between the three major factors that determine renal phosphate excretion (i.e. net inflow from gut, bone and soft tissue, tubular reabsorption, and glomerular filtration rate). By calculating tubular reabsorption of phosphate $\left(1-\mathrm{C}_{\mathrm{PO} 4}: \mathrm{C}_{\text {creat }}\right)$ and using a nomogram (Figure 4), renal phosphate threshold normalized for the glomerular filtration rate $\left(\mathrm{Tm}_{\mathrm{Pi}}=\mathrm{Tm}_{\mathrm{PO} 4} / \mathrm{GFR}\right)$ can be calculated. The normal range is $2.5-4.2 \mathrm{mg}$ per $100 \mathrm{ml} .{ }^{94}$

Low $\operatorname{Tm}_{\mathrm{Pi}}$ in the hypophosphatemic patient indicates an appropriate renal response to hypophosphatemia, and usually implicates gastrointestinal loss or intracellular shift. A high $\mathrm{Tm}_{\mathrm{Pi}}$ in hypophosphatemia is indicative of increased renal excretion secondary to a PTH-mediated mechanism, Fanconi syndrome, XLH, autosomal dominant hypophosphatemic rickets or oncogenic osteomalacia. As there is little evidence that moderate hypophosphatemia $(1.0-2.5 \mathrm{mg} / \mathrm{dl}$ [0.3-0.8 mmol/l]) has significant clinical consequences in humans, there is no need for aggressive intravenous phosphate replacement. This is particularly true in situations associated with intracellular shifts of phosphorus. As there is evidence indicating that respiratory parameters of ventilated patients improve after treatment of moderate hypophosphatemia, phosphorus should be repleted into the normal range in this clinical setting.

The role of phosphate replacement in management of diabetic ketoacidosis is controversial, particularly with respect to the effect of phosphate intermediates on tissue oxygenation. From a prospective, randomized study it was concluded that phosphate repletion might accelerate regeneration of erythrocyte 2,3-DPG in patients with diabetic ketoacidosis, but repletion had no demonstrable influence on tissue oxygenation or clinical response to lowdose insulin therapy. Phosphate replacement therapy exacerbated hypocalcemia, a finding that warrants caution when contemplating use of this treatment. ${ }^{95}$

It is generally recommended that patients with severe hypophosphatemia $(<1.0 \mathrm{mg} / \mathrm{dl}$ $[0.3 \mathrm{mmol} / \mathrm{l}])$ are treated to avoid potential detrimental consequences. Administration of inorganic phosphate shows that the phosphorus storage compartments are heterogeneous. Phosphate enters several pools at varying rates 
that can be altered by many factors, including simultaneous administration of glucose or insulin. ${ }^{96}$ Lentz and colleagues proposed that, in a given hypophosphatemic patient, rapid shifting of phosphorus between compartments can occur during phosphorus infusion. Accordingly, neither the phosphorus compartments utilized, nor the body's deficit and response to replacement, can be predicted. These authors recommended parenteral therapy for all causes of hypophosphatemia, at an initial dose of $0.08 \mathrm{mmol} / \mathrm{kg}$ body weight $(2.5 \mathrm{mg} / \mathrm{kg}$ body weight) if the onset was recent and the case uncomplicated, or $0.16 \mathrm{mmol} / \mathrm{kg}$ body weight $(5.0 \mathrm{mg} / \mathrm{kg}$ body weight) if hypophosphatemia was long-standing and caused by multiple factors. They also suggest that each dose be given intravenously over 6 h. ${ }^{97}$

Ten adult normocalcemic patients with severe hypophosphatemia $(\leq 1.0 \mathrm{mg} / \mathrm{dl}[0.3 \mathrm{mmol} / \mathrm{l}])$, two or more clinical reasons for hypophosphatemia, and normal renal function, were studied prospectively. These patients were treated with $0.32 \mathrm{mmol}$ phosphorus per $\mathrm{kg}$ of body weight infused intravenously over $12 \mathrm{~h}$. The investigators concluded that this dose was safe and efficacious. ${ }^{98}$ By contrast, intravenous phosphate therapy for hypophosphatemia has been reported to cause a precipitous fall in serum calcium concentration, hypotension and acute renal failure. ${ }^{99}$ In addition to the total dose, rate of administration has always been a concern in the parenteral treatment of hypophosphatemia. Potassium phosphate at a rate of $20 \mathrm{mmol} / \mathrm{h}(15 \mathrm{mmol} / \mathrm{h}$ elemental phosphorus) for either 1 or $2 \mathrm{~h}$ was administered to 85 patients. Vital signs and cardiac rhythm were continuously monitored. There were no changes in heart rhythm, serum calcium or magnesium concentrations, blood pressure or clinical status. ${ }^{100}$ In a similar study in a surgical intensive care unit, 11 patients with serum phosphorus concentrations between 1.6 and $1.9 \mathrm{mg} / \mathrm{dl}(0.5-0.6 \mathrm{mmol} / \mathrm{l})$ were treated with $15 \mathrm{mmol}$ intravenous sodium or potassium (if serum potassium concentration was $<3.5 \mathrm{mmol} / \mathrm{l}$ ) phosphate over $2 \mathrm{~h}$. The same dose could be repeatedly administered to a maximum of $45 \mathrm{mmol}$ in a $24 \mathrm{~h}$ period if either the $6 \mathrm{~h}$ or $18-24 \mathrm{~h}$ follow-up postinfusion serum phosphorus concentration remained at below $2 \mathrm{mg} / \mathrm{dl}(0.6 \mathrm{mmol} / \mathrm{l})$. All patients were successfully repleted using this protocol without any major adverse effects. ${ }^{101}$
Box 1 Indications for different modes of therapy in hypophosphatemia.

- Severe hypophosphatemia $(<1.0 \mathrm{mg} / \mathrm{dl}$ $[0.3 \mathrm{mmol} / \mathrm{l}])$ in critically ill, intubated patients or those with clinical sequelae of hypophosphatemia (e.g. hemolysis) should be managed with intravenous replacement therapy $(0.08-0.16 \mathrm{mmol} / \mathrm{kg})$ over $2-6 \mathrm{~h}$

- Moderate hypophosphatemia (1.0-2.5 mg/dl [0.3-0.8 mmol/l]) in patients on a ventilator should be managed with intravenous replacement therapy $(0.08-0.16 \mathrm{mmol} / \mathrm{kg})$ over $2-6 \mathrm{~h}$

- Moderate hypophosphatemia (1.0-2.5 mg/dl [0.3-0.8 mmol/l]) in nonventilated patients should be managed with oral replacement therapy ( $1,000 \mathrm{mg} /$ day)

- Mild hypophosphatemia should be managed with oral replacement therapy $(1,000 \mathrm{mg} /$ day $)$

Although several studies support treatment of hypophosphatemic patients with rapid phosphorus infusion, the use of intravenous phosphorus-containing solutions is best justified in critically ill intubated patients when it has been shown that hypophosphatemia might prolong intubation. Other clinical sequelae, such as severe hemolytic anemia, might also warrant rapid repletion. Patients with moderate hypophosphatemia should be repleted orally unless they are on a ventilator (Box 1).

\section{CONCLUSIONS}

Hypophosphatemia in hospitalized patients is often associated with refeeding, chronic alcohol use, antacid therapy, respiratory alkalosis, correction of chronic respiratory acidosis and diabetic ketoacidosis. Severe hypophosphatemia $(\leq 1.0 \mathrm{mg} / \mathrm{dl}$ $[0.3 \mathrm{mmol} / \mathrm{l}])$ can cause respiratory failure, delay weaning from the ventilator, and increase the duration of intensive care and hospitalization. Myocardial contractility is impaired when serum phosphorus concentration falls below $1.0 \mathrm{mg} / \mathrm{dl}$ $(0.3 \mathrm{mmol} / \mathrm{l})$, but this does not seem to cause clinical congestive heart failure. The response to phosphorus repletion is highly variable between patients. Hemolytic anemia has been reported in patients with rapidly falling serum phosphorus concentration or very severe hypophosphatemia. Moderate hypophosphatemia has no effect on myocardial contractility but does reduce diaphragmatic contractility. 


\section{KEY POINTS}

- The kidney is a key regulator of phosphorus homeostasis

- Hypophosphatemia results from inadequate phosphorus intake/intestinal absorption, redistribution from extracellular to intracellular compartments, and/or excessive excretion

- Aggressive intravenous phosphate repletion $(0.08-0.16 \mathrm{mmol} / \mathrm{kg}$ over $2-6 \mathrm{~h})$ is generally only necessary when hypophosphatemia is severe

- Untreated severe hypophosphatemia (serum phosphorus $<1.0 \mathrm{mg} / \mathrm{dl}[0.32 \mathrm{mmol} / \mathrm{l}]$ ) can lead to hemolysis, rhabdomyolysis, respiratory failure and left ventricular dysfunction

\section{References}

1 Camp MA and Allon M (1990) Severe hypophosphatemia in hospitalized patients. Miner Electrolyte Metab 16: 365-368

2 Reilly RF (2005) Disorders of serum phosphorus. In Nephrology in 30 Days, 161-176 (Eds Reilly RF and Perazella MA) New York: McGraw Hill

3 Portale AA et al. (1987) Dietary intake of phosphorus modulates the circadian rhythm in serum concentration of phosphorus: implications for the renal production of 1,25-dihydroxyvitamin D. J Clin Invest 80: 1147-1154

4 Murer Het al. (2004) The sodium phosphate cotransporter family SLC34. Pflugers Arch 447: 763-767

5 Favus MJ (2002) Intestinal absorption of calcium, magnesium, and phosphorus. In Disorders of Bone and Mineral Metabolism, 48-73 (Eds Coe FL and Favus MJ) Philadelphia: Lippincott Williams and Wilkins

6 Segawa $\mathrm{H}$ et al. (2004) Intestinal $\mathrm{Na}-\mathrm{P}_{\mathrm{i}}$ cotransporter adaptation to dietary $\mathrm{P}_{\mathrm{i}}$ content in vitamin $\mathrm{D}$ receptor null mice. Am J Physiol Renal Physiol 287: F39-F47

7 Capuano $P$ et al. (2005) Intestinal and renal adaptation to a low- $\mathrm{P}_{\mathrm{i}}$ diet of type II NaP $\mathrm{N}_{\mathrm{i}}$ cotransporters in vitamin $\mathrm{D}$ receptor- and $1 \mathrm{aOHase-deficient} \mathrm{mice.} \mathrm{Am}$ J Physiol Cell Physiol 288: C429-C434

8 Xu H et al. (2001) Regulation of the human sodiumphosphate cotransporter $\mathrm{NaP}_{\mathrm{j}}$-llb gene promoter by epidermal growth factor. Am J Physiol Cell Physiol 280: $\mathrm{C} 628-\mathrm{C} 636$

$9 \mathrm{Xu} \mathrm{H}$ et al. (2003) Regulation of intestinal $\mathrm{NaP}_{\mathrm{i}}-\mathrm{Ilb}$ cotransporter gene expression by estrogen. Am J Physiol Gastrointest Liver Physiol 285: G1317-G1324

10 Palmada M et al. (2004) Regulation of intestinal phosphate cotransporter $\mathrm{NaPi}$ llb by ubiquitin ligase Nedd4-2 and by serum- and glucocorticoiddependent kinase 1. Am J Physiol Gastrointest Liver Physiol 287: G143-G150

11 Murer $\mathrm{H}$ et al. (2000) Proximal tubular phosphate reabsorption: molecular mechanisms. Physiol Rev 80: 1373-1409

12 Hernando $\mathrm{N}$ et al. (2005) Recent advances in renal phosphate transport. Ther Apher Dial 9: 323-327

13 Bacic D et al. (2004) Novel aspects in regulated expression of the renal type lla $\mathrm{Na} / \mathrm{P}_{\mathrm{i}}$-cotransporter. Kidney Int Supp/ S5-S12

14 Suki WN (2004) Phosphorus deficiency and hypophosphatemia. In Cecil Textbook of Medicine, 699-701 (Eds Goldman L and Bennett JC) Philadelphia: WB Saunders
15 Pivnick EK et al. (1995) Rickets secondary to phosphate depletion: a sequella of antacid use in infancy. Clin Pediatr (Phila) 34: 73-78

16 Shields HM (1978) Rapid fall of serum phosphorus secondary to antacid therapy. Gastroenterology 75 : 1137-1141

17 Lotz M et al. (1968) Evidence for a phosphorusdepletion syndrome in man. N Engl J Med 278: 409-415

18 Marvous E et al. (1964) Effects of alkalosis on plasma concentration and urinary excretion of inorganic phosphate in man. $J$ Clin Invest 43: 138-149

19 Hoppe A et al. (1982) Effect of respiratory alkalosis on renal phosphate excretion. Am J Physiol 243: F471-F475

20 Milionis HJ et al. (1999) Acid-base abnormalities in a patient with hepatic cirrhosis. Nephrol Dial Transplant 14: 1599-1601

21 Knochel JP et al. (1977) The mechanism of hypophosphatemia in acute heat stroke. JAMA 238: 425-426

22 Bernuau J (1990) Fulminant and subfulminant vira hepatitis. Rev Prat 40: 1652-1655

23 Schnitker MA et al. (1951) A clinical study of malnutrition in Japanese prisoners of war. Ann Intern Med 35: 69-96

24 Marinella MA (2003) The refeeding syndrome and hypophosphatemia. Nutr Rev 61: 320-323

25 Fiske CH (1921) Inorganic phosphate and acid excretion in the postabsorptive period. J Biol Chem 49: $171-181$

26 Sokhey SS (1924) The relationship of phosphates to carbohydrate metabolism; the relationship of the changes in phosphate excretion caused by insulin and sugar. Biochem J 18: 1170-1184

27 Pollack Het al. (1934) Serum phosphate changes induced by injections of glucose into dogs under various conditions. Am J Physiol 110: 117-128

28 Milionis HJ et al. (1999) Acid-base and electrolyte abnormalities in patients with acute leukemia. $A m J$ Hematol 62: 201-207

29 Steiner M et al. (2000) Severe hypophosphatemia during hematopoietic reconstitution after allogeneic peripheral blood stem cell transplantation. Bone Marrow Transplant 25: 1015-1016

30 Brasier AR et al. (1988) Hungry bone syndrome: clinical and biochemical predictors of its occurrence after parathyroid surgery. Am J Med 84: 654-660

31 Laaban JP et al. (1989) Hypophosphatemia induced by mechanical ventilation in patients with chronic obstructive pulmonary disease. Crit Care Med 17: $1115-1120$

32 Pfister MF et al. (1999) cAMP-dependent and -independent downregulation of type II Na-Pi cotransporters by PTH. Am J Physiol 276: F720-F725

33 Saito K et al. (1993) Effect of parathyroid-hormonerelated protein on sodium-dependent phosphate transport in renal brush border membrane vesicles in rats: comparison with parathyroid hormone. Nephron 64: 600-604

34 Knochel JP (2000) Clinical and physiologic phosphate disturbances. In The Kidney Physiology and Pathophysiology, 1905-1934 (Eds Seldin DW and Giebisch G) Philadelphia: Lippincott, Williams and Wilkins

35 Breton G et al. (2004) Tubulopathy consecutive to tenofovir-containing antiretroviral therapy in two patients infected with human immunodeficiency virus-1. Scand J Infect Dis 36: 527-528

36 Kazama l et al. (2004) Adult onset Fanconi syndrome: extensive tubulo-interstitial lesions and glomerulopathy in the early stage of Chinese herbs nephropathy. Clin Exp Nephrol 8: 283-287 
37 Green J et al. (2001) Evidence for a PTHindependent humoral mechanism in post-transplant hypophosphatemia and phosphaturia. Kidney Int 60: 1182-1196

38 Higgins RM et al. (1990) Hypophosphataemia after renal transplantation: relationship to immunosuppressive drug therapy and effects on muscle detected by 31P nuclear magnetic resonance spectroscopy. Nephrol Dial Transplant 5: 62-68

39 Schapira D et al. (1995) Tumor-induced osteomalacia. Semin Arthritis Rheum 25: 35-46

40 Rowe PS (2004) The wrickkened pathways of FGF23, MEPE and PHEX. Crit Rev Oral Biol Med 15: 264-281

41 Kobayashi Ket al. (2005) Expression of FGF23 is correlated with serum phosphate level in isolated fibrous dysplasia. Life Sci [doi: 10.1016/ j.Ifs.2005.09.052]

42 Fuller TJ et al. (1976) Reversible changes of the muscle cell in experimental phosphorus deficiency. J Clin Invest 57: 1019-1024

43 Knochel JP et al. (1978) Hypophosphatemia and rhabdomyolysis. J Clin Invest 62: 1240-1246

44 Brautbar N et al. (1983) Impaired energy metabolism in skeletal muscle during phosphate depletion. Kidney Int 24: 53-57

45 Yoshida Y et al. (2002) Rhabdomyolysis, hepatitis and multiple hematological disorders associated with alcohol abuse: a case report. J Med 33: 3-8

46 Kumar D et al. (1999) Rhabdomyolysis complicating unrecognized hypophosphatemia in an alcoholic patient. Can J Gastroenterol 13: 165-167

47 Funabiki Y et al. (1998) Disturbance of consciousness associated with hypophosphatemia in a chronically alcoholic patient. Intern Med 37: 958-961

48 Singhal PC et al. (1992) Prevalence and predictors of rhabdomyolysis in patients with hypophosphatemia. Am J Med 92: 458-464

49 Altuntas $Y$ et al. (2002) Rhabdomyolysis and severe haemolytic anaemia, hepatic dysfunction and intestinal osteopathy due to hypophosphataemia in a patient after Billroth II gastrectomy. Eur J Gastroenterol Hepatol 14: 555-557

50 Elisaf MS et al. (1997) Mechanisms of hypophosphataemia in alcoholic patients. Int J Clin Pract 51: 501-503

51 Urbano-Marquez A et al. (1989) The effects of alcoholism on skeletal and cardiac muscle. N Engl J Med 320: 409-415

52 Hallgren R et al. (1980) Serum and urinary myoglobin in alcoholics. Acta Med Scand 208: 33-39

53 Ryback RS et al. (1980) Clinical relationships between serum phosphorus and other blood chemistry values in alcoholics. Arch Intern Med 140: 673-677

54 Wada S et al. (1992) A case of anorexia nervosa with acute renal failure induced by rhabdomyolysis; possible involvement of hypophosphatemia or phosphate depletion. Intern Med 31: 478-482

55 Robertson NJ (1985) Fatal overdose from a sustainedrelease theophylline preparation. Ann Emerg Med 14: 154-158

56 Johnson $\mathrm{CH}$ et al. (1991) Acute barium poisoning with respiratory failure and rhabdomyolysis. Ann Emerg Med 20: 1138-1142

57 Dastur DK et al. (1975) Nature of muscular change in osteomalacia: light- and electron-microscope observations. J Pathol 117: 211-228

58 Travis SF et al. (1971) Alterations of red-cell glycolytic intermediates and oxygen transport as a consequence of hypophosphatemia in patients receiving intravenous hyperalimentation. $N$ Engl $J$ Med 285: 763-768
59 Lichtman MA et al. (1971) Reduced red cell glycolysis, 2,3-diphosphoglycerate and adenosine triphosphate concentration, and increased hemoglobin-oxygen affinity caused by hypophosphatemia. Ann Intern Med 74: 562-568

60 Nakao Ket al. (1962) A direct relationship between adenosine triphosphate-level and in vivo viability of erythrocytes. Nature 194: 877-878

61 Nakao M et al. (1961) Adenosine triphosphate and shape of erythrocytes. J Biochem (Tokyo) 49: 487-492

62 LaCelle PL (1970) Alteration of membrane deformability in hemolytic anemias. Semin Hematol 7: 355-371

63 Maduell F et al. (2003) Intradialysis hemolysis secondary to hypophosphatemia [Spanish]. Nefrologia 23: 85-88

64 Melvin JD et al. (2002) Severe hypophosphatemia: a rare cause of intravascular hemolysis. Am J Hematol 69: 223-224

65 Kaiser U et al. (2001) Haemolytic anaemia in a patient with anorexia nervosa. Acta Haematol 106: 133-135

66 Jacob HS et al. (1971) Acute hemolytic anemia with rigid red cells in hypophosphatemia. $N$ Engl J Med 285: 1446-1450

67 Craddock PR et al. (1974) Acquired phagocyte dysfunction: a complication of the hypophosphatemia of parenteral hyperalimentation. N Engl J Med 290: 1403-1407

68 Rasmussen A et al. (1988) Reduced function of neutrophils during routine postoperative glucose infusion. Acta Chir Scand 154: 429-433

69 Preston CJ et al. (1982) Intracellular inorganic phosphate and ATP levels in human blood erythrocytes, leucocytes and platelets in normal subjects and in diseases associated with altered phosphate metabolism. Adv Exp Med Biol 151: 147-155

70 Gravelyn TR et al. (1988) Hypophosphatemiaassociated respiratory muscle weakness in a general inpatient population. Am J Med 84: 870-876

71 Aubier M et al. (1985) Effect of hypophosphatemia on diaphragmatic contractility in patients with acute respiratory failure. N Engl J Med 313: 420-424

72 Fiaccadori E et al. (1994) Hypophosphatemia and phosphorus depletion in respiratory and peripheral muscles of patients with respiratory failure due to COPD. Chest 105: 1392-1398

73 Fiaccadori E et al. (1990) Hypophosphatemia in course of chronic obstructive pulmonary disease: prevalence, mechanisms, and relationships with skeletal muscle phosphorus content. Chest 97: 857-868

74 Gustavsson CG et al. (1989) Acute respiratory failure in anorexia nervosa with hypophosphataemia. J Intern Med 225: 63-64

75 Hasselstrom L et al. (1986) Hypophosphatemia and acute respiratory failure in a diabetic patient. Intensive Care Med 12: 429-431

76 Brown EL et al. (1980) A case of respiratory failure complicated by acute hypophosphataemia. Anaesthesia 35: 42-45

77 Liu PY et al. (2004) Severe hypophosphatemia in a patient with diabetic ketoacidosis and acute respiratory failure. J Chin Med Assoc 67: 355-359

78 Fuller TJ et al. (1978) Reversible depression in myocardial performance in dogs with experimental phosphorus deficiency. J Clin Invest 62: 1194-1200

79 O'Connor LR et al. (1977) Effect of hypophosphatemia on myocardial performance in man. $N$ Engl J Med 297: 901-903

80 Vered Z et al. (1984) Left ventricular function in patients with chronic hypophosphatemia. Am Heart $J$ 107: $796-798$ 


\section{Competing interests}

The authors declared

they have no competing

interests.
81 Davis SV et al. (1988) Reversible depression of myocardial performance in hypophosphatemia. Am J Med Sci 295: 183-187

82 Vered l et al. (1990) Normal left ventricular performance in children with X-linked hypophosphatemic rickets: a Doppler echocardiography study. J Bone Miner Res 5: 469-474

83 Ognibene A et al. (1994) Ventricular tachycardia in acute myocardial infarction: the role of hypophosphatemia. South Med J 87: 65-69

84 DeFronzo RA et al. (1980) Hypophosphatemia and glucose intolerance: evidence for tissue insensitivity to insulin. N Engl J Med 303: 1259-1263

85 Seldin DW et al. (1950) The metabolism of glucose and electrolytes in diabetic acidosis. J Clin Invest 29: 552-565

86 Kono N et al. (1981) Alteration of glycolytic intermediary metabolism in erythrocytes during diabetic ketoacidosis and its recovery phase. Diabetes 30: 346-353

87 Shilo S et al. (1985) Acute hemolytic anemia caused by severe hypophosphatemia in diabetic ketoacidosis. Acta Haematol 73: 55-57

88 Peeters A et al. (1993) Wernicke's encephalopathy and central pontine myelinolysis induced by hyperemesis gravidarum. Acta Neurol Belg 93: 276-282

89 Junge O (1979) Acute polyneuropathy due to phosphate deficiency during parenteral feeding [German]. Fortschr Med 97: 335-338

90 Michell AW et al. (2003) Central pontine myelinolysis temporally related to hypophosphataemia. J Neurol Neurosurg Psychiatry 74: 820

91 Silvis SE et al. (1972) Paresthesias, weakness, seizures, and hypophosphatemia in patients receiving hyperalimentation. Gastroenterology 62: 513-520
92 Yagnik P et al. (1985) Peripheral neuropathy with hypophosphatemia in a patient receiving intravenous hyperalimentation. South Med J 78: 1381-1384

93 Bevington A et al. (1986) A study of intracellular orthophosphate concentration in human muscle and erythrocytes by $31 \mathrm{P}$ nuclear magnetic resonance spectroscopy and selective chemical assay. Clin Sci (Lond) 71: 729-735

94 Walton RJ et al. (1975) Nomogram for derivation of renal threshold phosphate concentration. Lancet 2: 309-310

95 Fisher JN et al. (1983) A randomized study of phosphate therapy in the treatment of diabetic ketoacidosis. J Clin Endocrinol Metab 57: 177-180

96 Levenson SM et al. (1953) Studies in phosphorus metabolism in man, III: the distribution, exchange and excretion of phosphorus in man using radioactive phosphorus (P32) as a tracer. J Clin Invest 32: 497-509

97 Lentz RD et al. (1978) Treatment of severe hypophosphatemia. Ann Intern Med 89: 941-944

98 Vannatta JB et al. (1983) High-dose intravenous phosphorus therapy for severe complicated hypophosphatemia. South Med J 76: 1424-1426

99 Shackney Set al. (1967) Precipitous fall in serum calcium, hypotension, and acute renal failure after intravenous phosphate therapy for hypercalcemia: report of two cases. Ann Intern Med 66: 906-916

100 Kruse JA et al. (1992) Rapid intravenous phosphorus replacement in critically ill patients. Crit Care Med $\mathbf{2 0}$ (Suppl): S104

101 Rosen GH et al. (1995) Intravenous phosphate repletion regimen for critically ill patients with moderate hypophosphatemia. Crit Care Med 23: 1204-1210 